Original Article

\title{
SIMAROUBA GLAUCA BARK EXTRACT MEDIATED SYNTHESIS AND CHARACTERISATION OF IRON OXIDE AND SILVER NANOPARTICLES AND THEIR ANTIBACTERIAL, CYTOTOXIC AND PHOTOCATALYTIC ACTIVITY
}

\author{
BEENA JOSE ${ }^{*}$, RIYA MARTIN ${ }^{1}$ \\ Department of Chemistry, Vimala College (Autonomous), Thrissur, Kerala 680009 \\ Email: drbeenajose@gmail.com
}

Received: 30 May 2020, Revised and Accepted: 04 Jul 2020

\begin{abstract}
Objective: The objective of the present study is the synthesis of iron oxide and silver nanoparticles using Simarouba glauca aqueous bark extract, characterization of the synthesized nanoparticles and evaluation of their antimicrobial, photocatalytic activity and cytotoxicity.

Methods: The iron oxide and silver nanoparticles were synthesized using Simarouba glauca aqueous bark extract and crystal structures of the nanoparticles were determined by UV-Visible spectroscopy, Transmission Electron Microscopy, Scanning Electron Microscopy, X-ray Diffraction and Fourier Transform Infrared Spectroscopy. The in vitro cytotoxicity of the silver nanoparticles was evaluated using Dalton's lymphoma ascites cells. The antibacterial assay of the silver nanoparticles was conducted using agar well diffusion method.

Results: The UV-Visible spectrum of iron oxide nanoparticle showed an absorption maximum at $280 \mathrm{~nm}$ and silver nanoparticles showed an absorption maximum at $436 \mathrm{~nm}$. This is XRD pattern of iron oxide nanoparticles exhibited a characteristic peak at 26.85 is of maghemite the corresponding miller indices is (211) and the synthesized iron oxide nanoparticles are amorphous in nature. TEM image reveals the size of the synthesized iron oxide nanoparticles in the range of 26-30 nm and the size of silver nanoparticles is in the range of $120-140 \mathrm{~nm}$.
\end{abstract}

Green synthesized iron nanoparticles using Simarouba glauca bark extract effectively degraded methylene blue dye.

Conclusion: This study showed that the synthesized iron oxide and silver nanoparticles using Simarouba glauca aqueous bark extract exhibited pronounced antibacterial, anticancer and photocatalytic activity and can be used in the textile industry and also as an external antiseptic in prevention and treatment of bacterial infections.

Keywords: Simarouba glauca, Green synthesis, Characterization, Iron oxide nanoparticle, Silver nanoparticle, Photocatalytic activity, Antibacterial activity, Cytotoxicity

(c) 2020 The Authors. Published by Innovare Academic Sciences Pvt Ltd. This is an open access article under the CC BY license (http://creativecommons.org/licenses/by/4.0/) DOI: http://dx.doi.org/10.22159/ijpps.2020v12i9.38510. Journal homepage: https://innovareacademics.in/journals/index.php/ijpps

\section{INTRODUCTION}

Green synthesis of nanoparticles is cost-effective, eco-friendly, nontoxic, large scale production can be done easily and acts as reducing and capping agent when compared to the chemical method [1]. Plantmediated biological synthesis of nanoparticles has gained importance only in recent years [2] and plant extracts reduce the metal ions in a shorter time as compared to microbes [3]. The synthesized nanoparticles can be used for the purification of water contaminated with carcinogenic textile dyes due to its photocatalytic activity.

Simarouba glauca is commonly known as 'Laxmitaru or 'paradise tree' belonging to family Simaroubaceae. The leaves and bark of Laxmitaru have a long history of medicinal use in the tropics, particularly in the treatment of malaria, fevers and dysentery. The leaves of Simarouba glauca exhibited antibacterial, antioxidant, hemolytic and thrombolytic activities [4]. The bark is used as a bitter tonic known as 'Orinoco Simaruba Oil'. A decoction is taken internally in the treatment of diarrhoea, dysentery, malaria, fevers, hemorrhages, intestinal parasites and colitis. Simarouba glauca seed exhibited in vitro cytotoxic activity against human epidermoid tumor cell line. Cytotoxic activity can be attributed to the cathin-6-one derivatives, limonoid and terpenoids present in the seeds $[5,6]$. The leaves of Simarouba glauca have been used as potential source of anticancer agents in traditional medicine [7]. Silver nanoparticles were synthesized using endophytic fungus Aspergillus niger isolated from Simarouba glauca leaf and its antibacterial and antioxidant activity were reported [8]. The biosynthesized silver nanoparticles using Simarouba glauca seed extract showed antibacterial and antifungal activity [9].

Literature survey showed that plant-mediated green synthesis of silver and iron oxide nanoparticles using Simarouba glauca bark extract has remained an unexplored research area. The aqueous bark extract of Simarouba glauca was added to the mixture of $\mathrm{FeCl}_{2}$ and $\mathrm{FeCl}_{3}$ solution and the color of the reaction medium was changed from yellow to black and that indicates the reduction of iron ions to iron nanoparticles. When aqueous bark extract of Simarouba glauca was added to silver nitrate solution, the pale dirty green colour of the extract changed to reddish-brown colour and the colour change confirmed the formation of silver nanoparticle.

The synthesized nanoparticles were characterized by UV-Vis spectrophotometer and the dispersity and morphology were studied by Scanning Electron Microscope (SEM) and Transmission Electron Microscope (TEM). The crystalline nature and purity of synthesized nanoparticles were revealed by X-ray diffraction (XRD) technique. FTIR spectrum was examined to identify the effective functional molecules responsible for the reduction and stabilization of nanoparticles synthesized by Simarouba glauca aqueous bark extract.

The need for the purification of the wastewater is of great concern to today's world and the water containing organic pollutants such as dyes coming out from textile industries affects the biological cycle. Many studies have shown that dyes such as methylene blue and crystal violet are carcinogenic and mutagenic [10]. In this study, we have studied the photodegradation of the methylene blue by iron oxide nanoparticles synthesized using Simarouba glauca bark extract.

Size, shape, functional groups and morphology of synthesized nanoparticle were determined with Fourier Transform Infrared spectroscopy (FTIR), UV-Vis spectrometry, Scanning electron microscopry (SEM), Transmission electron microscopy (TEM). The anti-antimicrobial efficacy of the synthesized nanoparticle was investigated via agar well diffusion method. The UV-Visible 
spectrum of synthesized nanoparticles was studied. From the FTIR spectroscopic analysis of the different functional groups present in the Simarouba glauca bark extract was identified. It showed the ability of this plant to act as reducing agents and stabilizers of nanoparticles.

The present study is a subject of great interest and the synthesis and characterization of silver and iron oxide nanoparticles from Simarouba glauca bark extract were reported for the first time. The synthesized nanoparticles using Simarouba glauca bark extract showed significant catalytic activity in the photodegradation of methylene blue and hence it can be used as a promising candidate for the purification of wastewater contaminated with dyes from textile industries.

\section{MATERIALS AND METHODS}

\section{Plant material}

Bark of Simarouba glauca was collected from Thrissur district, Kerala, during November 2017 and authenticated by Dr. Sheeja Tharakan, Department of Botany, Vimala College, Thrissur and the voucher specimen no VMA-SGB-003 was kept in the herbarium of the department for future reference.

\section{Chemical reagent}

Ferrous chloride, ferric chloride, sodium hydroxide, silver nitrate, Mueller Hinton agar, DMSO, methylene blue, ciprofloxacin, potassium bromide.

\section{Preparation of Simarouba glauca aqueous bark extract}

Bark was washed thoroughly with water and then dried. About 20g of dried bark piece was taken in a beaker and $150 \mathrm{ml}$ of distilled water was added and boiled for an hour with continuous stirring. It was then concentrated by evaporation and the volume of the solution was reduced to $50 \mathrm{ml}$. After cooling the solution, it was decanted and poured into another beaker [11].

\section{Preparation of iron oxide nanoparticles}

The preparation of nanoparticles was carried out with help of a magnetic stirrer. Fifty $\mathrm{ml}$ of $0.1 \mathrm{M} \mathrm{FeCl}_{2}$ solution was mixed with 100 $\mathrm{ml}$ of $0.1 \mathrm{M} \mathrm{FeCl} \mathrm{Fel}_{3}$ solution in a large conical flask and covered with cotton. The solution was stirred for $10 \mathrm{~min}$ with a magnetic stirrer and the temperature was kept at $80^{\circ} \mathrm{C}$. When the solution became yellow colour, $50 \mathrm{ml}$ of the plant extract was added to the conical flask. Stirred it again at $80{ }^{\circ} \mathrm{C}$ for about $5 \mathrm{~min}$ and the colour of the solution changed from yellow to black and the temperature was maintained at $80{ }^{\circ} \mathrm{C}$ throughout the experiment. $10 \mathrm{ml}$ of $\mathrm{NaOH}$ solution was added to it with constant stirring. After adding $\mathrm{NaOH}$ the solution was further stirred for $5 \mathrm{~min}$. The solution was then cooled and the froth formed was removed. After $10 \mathrm{~min}$ the plant residue was precipitated at the bottom of the conical flask. By putting it on a slanted surface, the solution became clear and decanted the solution to another beaker. Then the decanted solution was centrifuged. After centrifuging all the solution the nanoparticles participated at the bottom of the centrifuging tube were washed with distilled water for 2-3 times. The nano particles were then poured into a petri dish and covered it with a clean white paper. The nanoparticles obtained are dried at $40{ }^{\circ} \mathrm{C}$ under vaccum to obtain the iron oxide nanoparticles [12].

\section{Preparation of silver nanoparticle}

To synthesize silver nanoparticles, $90 \mathrm{ml}$ of $\mathrm{AgNO}_{3}$ solution was taken in a conical flask, which was covered with aluminium foil previously to prevent the entry of light. Ten ml of leaf extract was added to it dropwise slowly with constant shaking. This was placed on shaker for $30 \mathrm{~min}$. The colour change of solution appeared rapidly and the yellow colour changes to reddish-brown colour and the reaction was completed after $2 \mathrm{~h}$. The $\mathrm{pH}$ of the solution was adjusted to 9 by adding necessary quantity of $\mathrm{NaOH}$ and it was observed that at pH 9 sudden colour change appeared than at low $\mathrm{pH}$ and the solution was allowed to rest in dark overnight [13]. The synthesized nanoparticles were characterized by UV-Visible, FTIR spectroscopy, SEM, TEM and XRD analyses. The evaluation of in vitro cytotoxicity and antibacterial activity was also conducted.

The Simarouba glauca aqueous bark extract is depicted to contain important phytochemicals such as flavones, tannins, and other polyphenols which act as a reducing agent to give the reduced iron and silver ions. As the plant extract was mixed in the aqueous solution of the silver ion and iron ion, it started to change the color due to the reduction of silver ion and iron ion, which may be the indication of the formation silver and iron oxide nanoparticles. High yield of silver and iron oxide nanoparticles was observed at $\mathrm{pH} 9$. The in vitro cytotoxicity, antibacterial activity of silver nanoparticles and dye degradation by iron oxide nanoparticles were carried out.

\section{Characterization of the nanoparticles}

The crystal structures of the silver and iron oxide nanoparticles were determined by X-Ray diffraction analysis using X-Ray Diffraction Unit (XRD) Pan Alytical, X-Pert pro, the Netherlands operating at $40 \mathrm{kV}$ with $2 \mathrm{sec}$ time interval at room temperature. The morphology of the prepared nanoparticles was determined by Scanning Electron Microscopy (JEOL Model/JSM-6390LV). The sample was analysed by Tranmission Electron Microscopy (TEM) to determine the size and morphology of the particles. TEM analysis was done using a JEOL/JSM-2100F. FTIR spectrum was recorded using FTIR spectrometer (Model RXI, Make Perkin Elemer) in the range of $4000-400 \mathrm{~cm}^{-1}$ using $\mathrm{KBr}$ pellet method. The surface Plasmon resonances of synthesized nanoparticles were studied by a UV-Visible double beam spectrometer (Varian, Cary 5000) in the range of $175-800 \mathrm{~nm}$.

\section{RESULTS AND DISCUSSION}

Characterization of iron oxide nanoparticles from aqueous bark extract of Simarouba glauca

UV-Visible spectroscopy is a simple and reliable method for monitoring the stability of nanoparticle solutions and the bioreduction of $\mathrm{Ag}^{+}, \mathrm{Fe}^{2+}$ and $\mathrm{Fe}^{3+}$ aqueous solutions were monitored by periodic sampling of the mixture and subsequently measuring UV-Vis spectra. The surface plasmon resonances (SPR) of iron oxide nanoparticles synthesized from the aqueous bark extract of Simarouba glauca have been studied by a UV-Visible double-beam spectrometer. The absorption of visible radiations due to the excitation of SPR, imparts various colours to nanoparticles. As the nanoparticles size changes, colour of the solution also changes. So UV-Vis absorption spectrum is quite sensitive to the formation of nanoparticles and both the nanoparticles and leaf extract were subjected to UV-Visible study.

UV-Vis spectral analysis was done by using UV-Vis spectrophotometer at the range of $200-500 \mathrm{~nm}$ and observed the absorption peaks at $436 \mathrm{~nm}$ for silver and $280 \mathrm{~nm}$ for iron oxide nanoparticles, respectively. The characteristic absorption peak occurs at the wavelength in the range of 200 to $300 \mathrm{~nm}$ indicated the formation of iron oxide nanoparticles [14]. The peak observed between 200-300 $\mathrm{nm}$ are of polyphenols. This can be attributed the fact that polyphenols in Simarouba glauca bark extract not only served as capping agents that reduced the aggregation of iron oxide and silver nanoparticles but also served as the reducing agents for the synthesis of nanoparticles [15]. Consequently, the stability and reactivity of iron oxide and silver nanoparticles was enhanced, which was confirmed by the subsequent SEM and TEM images. That silver nanoparticles exhibited reddish-brown colour in aqueous solution due to the excitation of surface plasmon vibrations in silver nanoparticles. Broadening of peak indicated that the particles are polydispersed.

FTIR measurements were carried out to identify the possible biomolecules in the aqueous bark extract responsible for the reduction of ions and also the capping agents responsible for the stability of the biogenic nanoparticle solution. The result of FTIR confirmed that the aqueous bark extract of Simarouba glauca is having a potential in reducing and stabilizing the iron oxide and silver nanoparticles. 


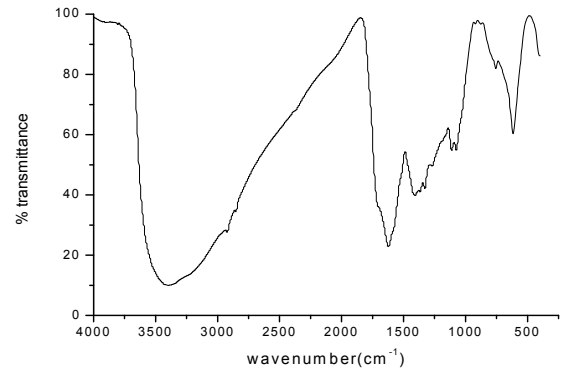

Fig. 1: FTIR of iron oxide nanoparticle

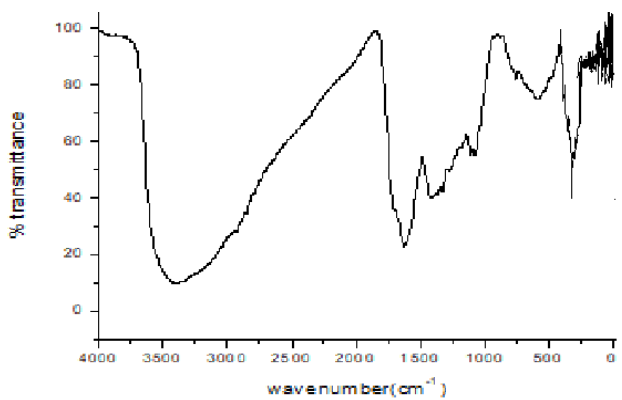

Fig. 2: FTIR of silver nanoparticle

The different functional groups present in Simarouba glauca aqueous bark extract were determined by the FTIR studies. The band between $3500-3300 \mathrm{~cm}^{-1}$ corresponds to the stretching of $\mathrm{O}-\mathrm{H}$ of phenols and that of $\mathrm{N}-\mathrm{H}$ bond of amines present in the extract. The presence of phenolic compounds in Simarouba glauca extract is responsible for the formation and stabilization of synthesized nanoparticles. Peaks at $1740-1720 \mathrm{~cm}^{-1}$ indicated the presence of saturated aldehydes. These reducing sugars in the solution could be responsible for the reduction of metal ions and the formation of the corresponding metal nanoparticles [16]. This suggests that the biological molecules could possibly perform dual functions of formation and stabilization of both iron oxide and silver nanoparticles in the aqueous medium.

The FTIR spectrum of iron oxide nanoparticles shows bands at $3410.47 \mathrm{~cm}^{-1}$ and $1624.02 \mathrm{~cm}^{-1}$ corresponding to $\mathrm{O}-\mathrm{H}$ stretching and bending bands. The frequencies at low wavenumbers $624 \mathrm{~cm}^{-1}$ come from vibrations of Fe-O bonds of iron oxide. The band at $624 \mathrm{~cm}^{-1}$ refers to $\mathrm{Fe}-\mathrm{O}$ stretches of maghemite $\left(\gamma-\mathrm{Fe}_{2} \mathrm{O}_{3}\right)$ [17]. The strong peak at $324 \mathrm{~cm}^{-1}$ in corresponds to silver nanoparticle [18]. From this result, it has been concluded that the soluble biomolecule group present in the Simarouba glauca bark extract acted as capping agents, preventing the aggregation of iron oxide and silver nanoparticles in the solution.

XRD analysis of iron oxide and silver nanoparticles synthesized using Simarouba Glauca aqueous bark extract

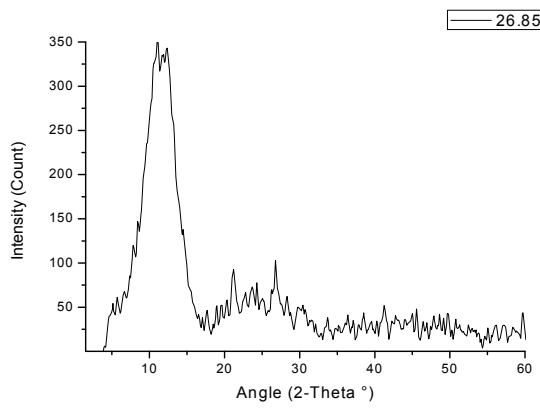

Fig. 3: XRD pattern of iron oxide nanoparticle

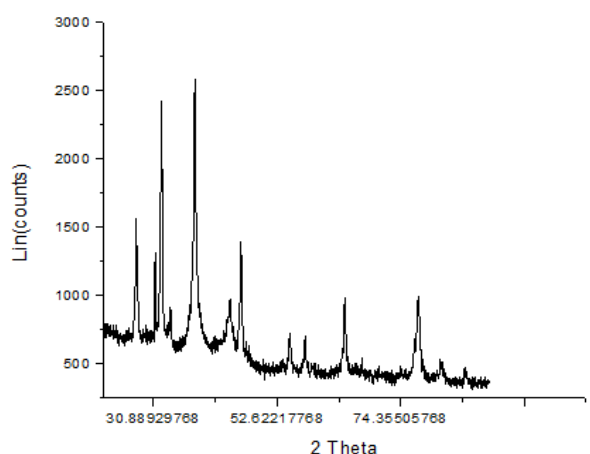

Fig. 4: XRD pattern of silver nanoparticle

The XRD pattern of iron oxide nanoparticle is given in fig. 1 . The crystallinity of the iron nanoparticle was examined by XRD and the

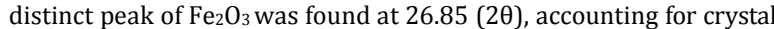
plane (211) and intense peak at $2 \mathrm{~h}=11.052$ was identified as polyphenols. Both iron oxide and iron oxohydroxide were observed in the iron nanoparticles synthesized by Simarouba glauca bark extract and are amorphous in nature [19].

The XRD pattern of silver nanoparticles showed 4 peaks at $2 \mathrm{~h}=38.16,44.28,64.51,77.45$ and these picks are corresponding to $111,200,220$ and 311 planes of Bragg's reflection of silver, respectively. The size of silver nanoparticle is $28 \mathrm{~nm}$. The peaks at $2 \theta=27.90^{\circ}, 32.16^{\circ}, 46.0^{\circ}$ were related to crystalline and amorphous organic phases. The presence of picks on planes lower than 30 are due to the existence of phytochemical compounds present in the bark of Simarouba glauca. The sharp and narrow diffraction peaks in the XRD spectrum indicated that the synthesized silver nanoparticles were pure and highly crystalline nature [20]

\section{SEM and TEM analysis of iron oxide and silver nanoparticles}

The images of the synthesized nanoparticles were taken by scanning electron microscopy that are given below:

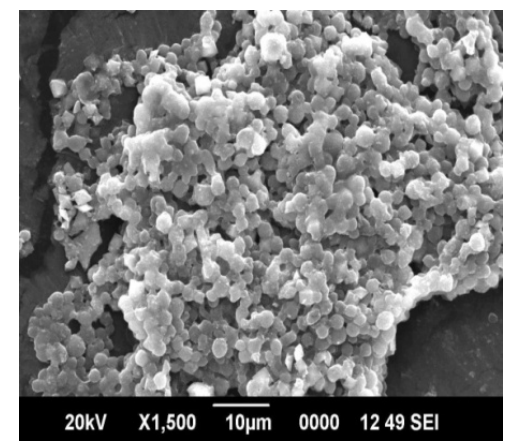

Fig. 5: SEM image of silver nanoparticle

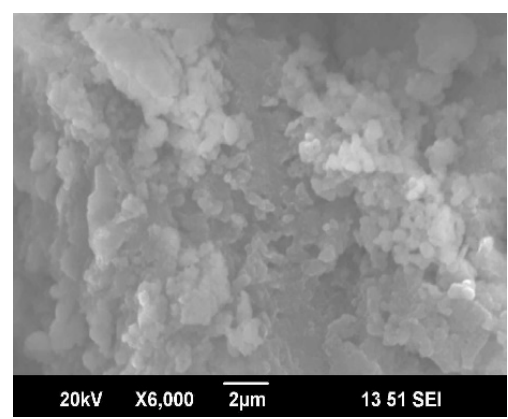

Fig. 6: SEM image of iron oxide nanoparticle 
The powdered sample was analyzed for the structure and morphology of the synthesized iron oxide and silver nanoparticles using SEM (fig. 5 and fig. 6). It is clear from the SEM images that the synthesized products are nanoparticles, which grown in a very highdensity and possessed almost uniform shape for silver nanoparticle and non-uniform for iron oxide nanoparticle. SEM image of the synthesized silver nanoparticles showed that most of the nanoparticles possessed spherical shape. The morphology of the synthesized iron oxide nanoparticles mostly appeared to be a porous and spongy and aggregated as irregular sphere shapes with rough surfaces. However, to obtain a clear size, shape and structural image of the nanoparticles the samples were analyzed using transmission electron microscopy (fig. 7 and fig. 8).

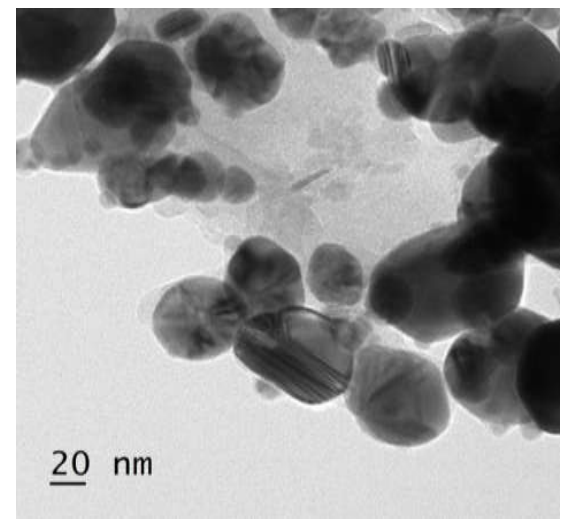

Fig. 7: TEM of silver nanoparticle

TEM image shows the size distribution and shape of nanoparticles based on the transmittance of the electron beam through an ultrathin specimen and transmission electron microscope image reveals the size of the synthesized silver nanoparticle is in the range of 120$140 \mathrm{~nm}$ and iron oxide nanoparticles is in the range of $26-30 \mathrm{~nm}$
TEM photographs showed spherical nanoparticles of iron oxide and silver, which appeared as deep dark spots and the dimensions are well consistent with the SEM observations [21].

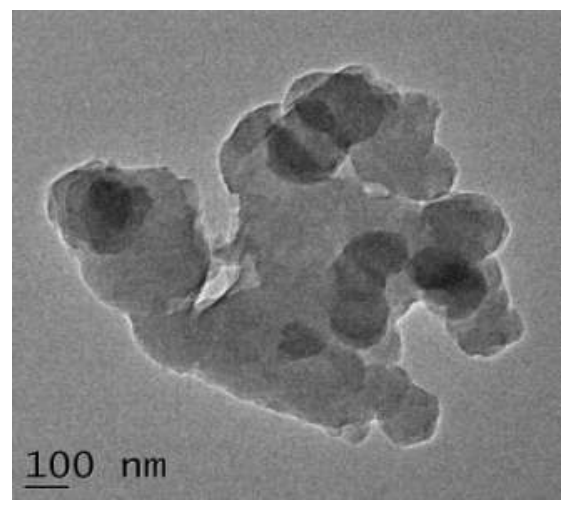

Fig. 8: TEM image of iron oxide nanoparticle

\section{In vitro cytotoxicity analysis of silver nanoparticles}

The silver nanoparticles prepared from Simarouba glauca bark extract were studied for the short term in vitro cytotoxicity using Daltons lymphoma ascites cells by Trypan Blue exclusion method. Viable cell suspension $\left(1 \times 10^{6}\right.$ cells in $\left.0.1 \mathrm{ml}\right)$ was added to tubes containing various concentrations of the test compound and the volume was made upto $1 \mathrm{ml}$ using phosphate-buffered saline (PBS). The Control tube contained only cell suspension and the assay mixture was intubated for 3 hour at $37^{\circ} \mathrm{C}$. Cell suspension was mixed with $0.1 \mathrm{ml}$ of $1 \%$ Trypan Blue and loaded on a hemocytometer and dead cells take up the blue colour of Trypan Blue while live cells do not take up the dye. The number of stained and unstained cells was counted separately [22]. The nanoparticle in various concentrations was applied to tumor-bearing mice and the percentage of cytotoxicity was calculated (table 1).

Table 1: Percentage cell death due to $S$. glauca bark extract and silver nanoparticle

\begin{tabular}{|c|c|c|c|c|c|}
\hline \multicolumn{6}{|c|}{ Percentage of cell death (\%) } \\
\hline & \multicolumn{5}{|c|}{ Drug concentration $(\mu \mathrm{g})$} \\
\hline & 100 & 50 & 20 & 10 & 5 \\
\hline 1. S. glaucabark extract & $17.64 \pm 0.18$ & $10.78 \pm 0.19$ & $7.76 \pm 0.12$ & $5.76 \pm 0.16$ & 0.00 \\
\hline 2. Silver nanoparticles & $100 \pm 0.16$ & $90.2 \pm 0.20$ & $78.43 \pm 0.22$ & $68.57 \pm 0.13$ & $66.66 \pm 0.18$ \\
\hline
\end{tabular}

$(\mathrm{n}=3$, mean $\pm \mathrm{SD})$

The cells treated with $5 \mu \mathrm{g}$ of Simrouba glauca bark extract do not have much effect on the Daltons Lymphoma Ascites cells (DLA) However, the silver nanoparticles exhibited significant activity and as the concentration of nanoparticles increases the cytotoxicity increases. At $100 \mu \mathrm{g}$, the silver nanoparticles synthesized using Simrouba glauca bark extract has $100 \%$ cell death of Daltons Lymphoma Ascites cells (DLA). Even though the Simarouba glauca bark extract has a cytotoxic effect, the table shows that the synthesized silver nanoparticles have more cytotoxic effect than the extract [23]. Silver nanoparticles can serve as anti-tumor agents by decreasing the progressive development of tumor cells.

\section{Antibacterial activity of silver nanoparticles}

The antibacterial activity was determined by the well diffusion method and Mueller Hinton Agar medium plates were prepared. The silver nanoparticles were synthesized using Simarouba glauca aqueous bark extract was prepared in $10 \mathrm{mg} / \mathrm{ml}$ concentration and 10, 20 and $40 \mu \mathrm{l}$ was tested against two Gram-positive (Staphylococcus aureus, Bacillus cereus) and Gram-negative
(Escherichia coli) cultures. The microorganisms used for this antibacterial activity evaluation were obtained from Microbial Type Cultute Collection and gene bank (IMTECH, Chandigrah, India). Wells of standard size were cut far enough to avoid overlapping rings of inhibition and the extracts were added to each well. DMSO was used as a negative control. Ciprofloxacin was used as standard. The petri dishes were incubated for $24 \mathrm{~h}$ at 37 ${ }^{\circ} \mathrm{C}$. The diameter of zone inhibition is the measure of antibacterial activity. The treatments were repeated thrice and the mean was taken [24]. The results of zone inhibition values are reported in table 2. Silver nanoparticles synthesized using Simarouba glauca aqueous bark extract exhibited high antibacterial activity against tested microorganisms. Nanosilver is considered one of the most viable alternatives to antibiotics because it seems to have high potential and due to their size, silver nanoparticles can enter cells and inhibit enzymatic systems and thereby alter their DNA synthesis. The studies proved that the antimicrobial activity of silver nanoparticles is high and it has less side effects to the mammalian cells [25]. 
Table 2: Inhibition zones formed by silver nanoparticles synthesized using Simarouba glauca aqueous bark extract

\begin{tabular}{|c|c|c|c|c|}
\hline \multirow{3}{*}{ Microorganisms } & \multicolumn{4}{|c|}{ Diameter of inhibition zones (mm) } \\
\hline & \multicolumn{2}{|c|}{ Silver nanoparticles $(\mu \mathrm{g})$} & \multicolumn{2}{|c|}{ Ciprofloxacin $(\mu \mathrm{g})$} \\
\hline & 10 & 20 & 40 & 10 \\
\hline 1. Bacillus cereus & $13+0.16$ & $15+0.20$ & $18+0.18$ & $19+0.12$ \\
\hline 2. Staphylococcus aureus & $16+0.18$ & $18+0.22$ & $20+0.16$ & $20+0.14$ \\
\hline 3. Escherichia coli & $12+0.14$ & $14+0.12$ & $18+0.22$ & $20+0.20$ \\
\hline
\end{tabular}

$(\mathrm{n}=3$, mean $\pm \mathrm{SD})$

The result showed that silver nanoparticles $(40 \mu \mathrm{g})$ exhibited significant activity against all tested microorganisms and were quite comparable to the standard antibiotic Ciprofloxacin $(10 \mu \mathrm{g})$ screened under similar conditions. The mechanism of the bactericidal activity of silver nanoparticles is due to the attachment of the silver nanoparticles to the cell wall. Silver nanoparticles disturb the permeability of the membrane by penetrating to the cell membrane and causing intracellular ATP leakage and cell death [26].

Degradation of methylene blue using iron oxide nanoparticle

Photocatalytic activity of the iron oxide nanoparticle synthesized using Simarouba glauca aqueous bark extract was evaluated by the decolorization of methylene blue dye in aqueous solution. The experiment was carried out in the presence of visible light irradiation without any catalyst. $10 \mathrm{mg}$ of methylene blue dye was added to $1000 \mathrm{ml}$ of double-distilled water used as stock solution and $10 \mathrm{mg}$ of iron oxide nanoparticles was added to $100 \mathrm{ml}$ of methylene blue dye solution. A control was also maintained without the addition of iron oxide nanoparticles. The reaction suspension was well mixed by stirring for $30 \mathrm{~min}$ to make the equilibrium of the working solution. The dispersion was then put under the sunlight and $10 \mathrm{ml}$ of the solution was withdrawn at $30 \mathrm{~min}$ time interval to evaluate the photocatalytic degradation of the dye. The solution was centrifuged for $1 \mathrm{~min}$ and filtered to remove the iron oxide catalyst particles before measuring the absorbance. That was characterized by UV-Visible spectroscopy [26].

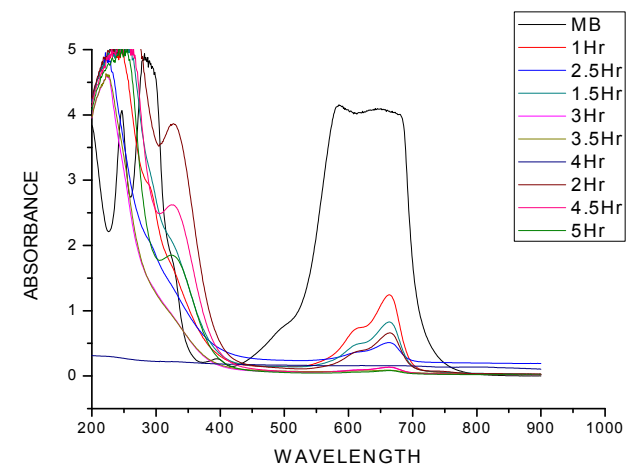

Fig. 9: UV Spectra of degradation of methylene blue

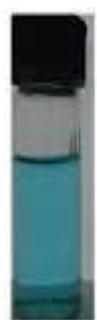

(a)

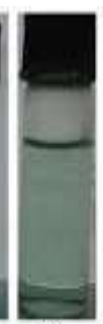

(b)

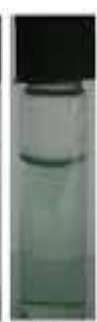

(c)

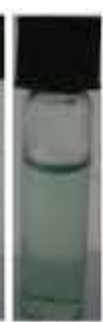

(d)

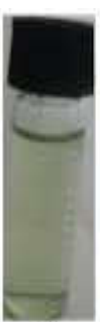

(e)

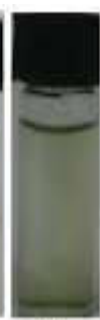

(f)

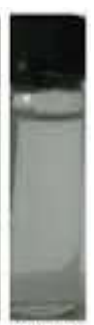

Control
Fig. 10: Methylene blue degradation
As shown in fig. 9, the intensity of peaks at $600 \mathrm{~nm}$ declined after reacting with iron oxide nanoparticles. This indicates that it was polyphenols which acted as a reducing agent in the synthesis of iron oxide nanoparticles using Simarouba glauca aqueous bark extract. In addition, the reduction potential of polyphenols is in the $0.3-0.8 \mathrm{~V}$ range and the reduction potential of Fe was only $0.44 \mathrm{~V}$. The broad absorption at wavelength in the range of 200-350 nm indicated the formation of iron oxide nanoparticles. UV spectrum has shown a continuous decrease in absorption and this indicates that high degradation rate and better efficiency were obtained by using Simarouba glauca aqueous bark extract.

\section{CONCLUSION}

In this work, the silver and iron oxide nanoparticles were synthesized by using with Simarouba glauca bark extract. The characterization of synthesized nanoparticles was done using UV SEM, TEM, XRD and FTIR. In the UV-Visible spectrum, the peak observed between 200-300 $\mathrm{nm}$ are of polyphenols and the polyphenols in Simarouba glauca bark extract served as both capping agents and reducing agents for the synthesis of iron oxide and silver nanoparticles.

The in vitro cytotoxicity analysis showed that the ability of the synthesized silver nanoparticle to destroy the tumor cell is greater than the Simarouba glauca bark extract. The green synthesized silver nanoparticles showed good antibacterial activity against the tested pathogens. The synthesized iron oxide nanoparticle could be used for the degradation of methylene blue and can be used for the wastewater treatment by the degradation of dye components.

The phytochemical screening of secondary metabolites in aqueous bark extract of Simarouba glauca revealed the presence of alkaloids, phenols, flavonoids, tannins, steroids, terpenoids, saponins, coumarin, quinines and these secondary metabolites possess high medicinal potential. The present results should be a very significant step toward a convenient and eco-friendly fabrication of iron oxide and silver nanoparticles, synthesized using aqueous Simarouba glauca bark extract, for various applications.

\section{ACKNOWLEDGEMENT}

The authors thank the Department of Science and Technology (Ministry of Science and Technology), Government of India, New Delhi, for the financial support under the DST-FIST grant.

\section{FUNDING}

Nil

\section{AUTHORS CONTRIBUTIONS}

All authors have contributed equally in the research work.

\section{CONFLICT OF INTERESTS}

\section{Declared none}

\section{REFERENCES}

1. Rai M, Yadav A, Gade A. CRC 675-current trends in phytosynthesis of metal nanoparticles. Crit Rev Biotechnol 2002;28:277-84.

2. Sravanthi M, Munikunar M, Ravichandra M, Hemalatha KP. Green synthesis and characterization of iron oxide nanoparticles in Wrightia tinctoria leaf extract and their antibacterial studies. Int J Curr Res Aca Rev 2016;4:30-44. 
3. Bharani M, Thirunethiran K, Varalakshmi B, Gayathri G, Lakshmi P. Synthesis and characterization of silver nanoparticles from Wrightia tinctoria. Int J Appl Biol Pharm Tech 2012;3:58-63.

4. Santhana LK, Sangeetha D, Sivamani S, Tamilarasan M, Rajesh TP, Anandraj B. In vitro, antibacterial, antioxidant, hemolytic, thrombolytic activities and phytochemical analysis of Simarouba glauca. Int J Pharm Sci Res 2014;5:432-7.

5. Govindaraju K, Khaleel BS, Ganesh KV, Singaravelu G. Silver, gold and bimetallic nanoparticles production using single-cell protein (Spirulina platensis) geitler. J Mater Sci 2008;43:5115-23.

6. Fausto JR, Raphel L, Aiko L, Steven M, Ivano M. Cytotoxic constituents of twigs of Simarouba Glauca collected from a plot in Southern Florida. Phytother Res 2005;19:136-40.

7. Jangale BL, Vogale TB, Aher PS, Toke NR, Shirangikar AN, Sanap NT. Antibacterial activity of Simarouba glauca against food born spoilage and pathogenic organism. Int J Pharm Sci Res 2012;28:497-500.

8. Hemashekhar B, Chandrappa CP, Govindappa M, Chandrasekhar N. Green synthesis of silver nanoparticles from endophytic fungus Aspergillus niger isolated from Simarouba glauca leaf and its antibacterial and antioxidant activity. Int J Eng Res Appl 2017;7:17-24

9. Ramesh J, Cathrine L, Gurupriya S, Pratheema P, Sahira BK. Biosynthesis of silver nanoparticles using Simarouba glauca seed extract and their anti-microbial activity. Int J Recent Sci Res 2018;9:24828-31.

10. Bruno Lellis C, Zani Favarp PJ, Alencar PJ, Cesar P. Effects of textile dyes on health and the environment and bioremediation potential of living organisms. Biotechnol Res Innov 2019;3:275-90.

11. Phull Q, Abbas AA, Raza H, Kim SJ, Zia M. Antioxidant, cytotoxic and antimicrobial activities of green synthesized silver nanoparticles from crude extract of Bergenia ciliate. Future J Pharm Sci 2016;6:320-44.

12. Amrutha S, Sridhar S. Green synthesis of magnetic iron oxide nanoparticle using leaves of Glycosmis maurintiana and their antibacterial activity against human pathogens. J Innov Pharm Biol Sci 2018;5:22-6.

13. Banerjee P, Satapathy M, Mukhopahayay A, Das P. Leaf extract mediated green synthesis of silver nanoparticles from widely available Indian plants: synthesis, characterization, antimicrobial property and toxicity analysis. Bioresour Bioprocess 2014;1:1-10.
14. Brajesh K, Smita K, Cumbal L, Debut A. Biogenic synthesis of iron oxide nanoparticles for 2-arylbenzimidazole fabrication. J Saudi Chem Soc 2014;18:364-9.

15. Ghandoor EH, Zidan HM, Mostafa KM, Ismail MI. Synthesis and some physical properties of magnetite $\left(\mathrm{Fe}_{3} \mathrm{O}_{4}\right)$ nanoparticles. Int J Electrochem Sci 2012;7:5734-45.

16. Pattanayak M, Nayak PL. Ecofriendly green synthesis of iron nanoparticles from various plants and spices extract. Int J Plant Anim Environ Sci 2013;3:68-78.

17. Kim T, Grady AN, Karl J, Justin S. Synthesis, characterization and alignment of magnetic carbon nanotubes tethered with maghemite nanoparticles. J Phys Chem 2010;114:6944-51.

18. Omkar P, Neelam D, Sharda D, Shobha W. Green synthesis of silver nanoparticle from purple acid phosphatase apoenzyme isolated from a new source Limonia acidissima. J Exp Nanosci 2016;11:28-37.

19. Amlan KD, Avinash M, Ruchi V. Datura inoxia leaf extract mediated one-step green synthesis and characterization of magnetite (Fe304) nanoparticles. J Pharm Nanotech 2014;2:21-4.

20. Tripathy A, Raichur AM, Chandrasekaran N, Prathna TC, Mukherjee A. Process variables in biomimetic synthesis of silver nanoparticles by aqueous extract of Azadirachta indica (Neem) leaves. J Nanopart Res 2010;12:237-6.

21. Amutha S, Sridhar S. Green synthesis of maganetic iron oxide nanoparticle using leaves of Glycosmis Mauritiana and their bacterial activity against human pathogen. J Innov Pharm Biol Sci 2018;5:22-6

22. Phull AR, Abbas QA, Raza H, Kim SJ, Zia M. Antioxidant, cytotoxic and antimicrobial activities of green synthesized silver nanoparticles from the crude extract of Bergenia ciliate. Future J Pharm Sci 2016;6:320-44

23. Nurul AH, Hock IC, Muggundha RR, Wai HT. Cytotoxicity of plant-mediated synthesis of metallic nanoparticles: a systematic review. Int J Mol Sci 2018;19:1725-48.

24. Deepa RH, Monnanda SN. Antibacterial activity of lianoid and arboreal species of Schefflera from Southern India. Asian J Pharm Clin Res 2020;13:46-50.

25. Baskaran C, Ratha BV. Green synthesis of silver nanoparticles using Coleus Forskohlii roots extract and its antibacterial and antifungal activity. Int J Drug Dev Res 2013;5:1-10.

26. Sheena V, Sunny K, Soumya J. Antimicrobial activity of carbon nanoparticles isolated from natural sources against pathogenic gram-negative and gram-positive bacteria. J Nanosci 2013;10:1-5 